\title{
Effects of glycaemia on glucose transport in isolated skeletal muscle from patients with NIDDM: in vitro reversal of muscular insulin resistance
}

\author{
J. R.Zierath ${ }^{1}$, D. Galuska ${ }^{1}$, L. A. Nolte ${ }^{1}$, A. Thörne ${ }^{2}$, J.Smedegaard Kristensen ${ }^{3}$, H. Wallberg-Henriksson \\ ${ }^{1}$ Department of Clinical Physiology, Karolinska Hospital, Karolinska Institute, Stockholm, Sweden \\ ${ }^{2}$ Department of Surgery, Huddinge Hospital, Stockholm, Sweden \\ ${ }^{3}$ Department of Diabetes Research, Novo Research Institute, Novo-Nordisk A/S, Bagsvaerd, Denmark
}

Summary We investigated the influence of altered glucose levels on insulin-stimulated 3-0-methylglucose transport in isolated skeletal muscle obtained from NIDDM patients $(n=13)$ and non-diabetic subjects $(n=23)$. Whole body insulin sensitivity was $71 \%$ lower in the NIDDM patients compared to the non-diabetic subjects $(p<0.05)$, whereas, insulin-mediated peripheral glucose utilization in the NIDDM patients under hyperglycaemic conditions was comparable to that of the non-diabetic subjects at euglycaemia. Following a $30-\mathrm{min}$ in vitro exposure to $4 \mathrm{mmol} / \mathrm{l}$ glucose, insulinstimulated 3-0-methylglucose transport (600 $\mathrm{pmol} / \mathrm{hin}$ sulin) was $40 \%$ lower in isolated skeletal muscle strips from the NIDDM patients when compared to muscle strips from the non-diabetic subjects. The impaired capacity for insulin-stimulated 3-0-methylglucose transport in the NIDDM skeletal muscle was normalized following prolonged $(2 \mathrm{~h}$ ) exposure to $4 \mathrm{mmol} / \mathrm{l}$, but not to $8 \mathrm{mmol} / 1$ glucose. Insulin-stimulated 3-0methylglucose transport in the NIDDM skeletal muscle exposed to $8 \mathrm{mmol} / 1$ glucose was similar to that of the non-diabetic muscle exposed to $5 \mathrm{mmol} / \mathrm{lglu}$ - cose, but was decreased by $43 \%(p<0.01)$ when compared to non-diabetic muscle exposed to $8 \mathrm{mmol} / 1 \mathrm{glu}-$ cose. Despite the impaired insulin-stimulated 3-0methylglucose transport capacity demonstrated by skeletal muscle from the NIDDM patients, skeletal muscle glycogen content was similar to that of the nondiabetic subjects. Kinetic studies revel a $\mathrm{K}_{\mathrm{m}}$ for 3-0methylglucose transport of 9.7 and $8.8 \mathrm{mmol} / \mathrm{l}$ glucose for basal and insulin-stimulated conditions, respectively. In conclusion, the impaired capacity for insulinstimulated glucose transport in skeletal muscle from patients with NIDDM appears to protect the cell from excessive glucose uptake under hyperglycaemic conditions. Furthermore, the in vitro normalization of the decreased insulin-stimulated glucose transport in NIDDM skeletal muscle following exposure to $4 \mathrm{mmol} / \mathrm{l}$ glucose suggests that glycaemia per se has a profound effect on the regulation of muscular glucose transport. [Diabetologia (1994) 37:270-277]

Key words Glucose transport, glucose kinetics, human skeletal muscle, insulin action, insulin resistance.
Received: 17 June 1993

and in revised form: 15 September 1993

Corresponding author: Dr. J.R. Zierath, Department of Clinical Physiology, Karolinska Hospital, Box 60500, S-171 76 Stockholm, Sweden

Abbreviations: NIDDM, Non-insulin-dependent diabetes mellitus; KHB, Krebs-Henseleit bicarbonate buffer; BSA, bovine serum albumin; ANOVA, analysis of variance; GLUT 4, insulin regulated glucose transporter.
Non-insulin-dependent diabetes mellitus (NIDDM) is a heterogeneous metabolic disorder characterized in part by an impairment in whole body glucose metabolism $[1,2]$. For patients with NIDDM, the defect in glucose metabolism appears to be localized in part to skeletal muscle $[3,4]$, a tissue which accounts for approximately $75 \%$ of whole body glucose utilization following insulin stimulation [5].

Chronic hyperglycaemia is a characteristic feature of patients with NIDDM, and has been implicated to play a central role in the development of peripheral insulin resistance and decreased beta-cell function [6]. In rat skeletal muscle $[7,8]$ and in cultured muscle cells 
[9], elevations in media glucose concentrations have been widely demonstrated to reduce insulin-stimulated glucose uptake and transport. Furthermore, short term $(24 \mathrm{~h})$ hyperglycaemia reduces whole body glucose uptake in vivo, in patients with insulin-dependent diabetes mellitus [10]. Thus, peripheral insulin resistance may develop as a physiological response to protect the tissue from an overload of glucose by "down regulating" cellular glucose transport $[6,10,11]$. Amelioration of hyperglycaemia in diabetic rats by phlorizin treatment [12], or in NIDDM patients by insulin therapy $[13,14]$ or dietary control $[15]$, improves impaired insulin action and glucose transport in isolated adipocytes. Yet, the influence of experimentally induced euglycaemia on the impaired capacity for insulin-stimulated glucose transport in isolated skeletal muscle from NIDDM patients remains to be defined.

The present study was undertaken to examine the effects of altered glucose levels on the glucose transport process in isolated skeletal muscle from patients with NIDDM and from non-diabetic subjects. For these purposes, we employed an open muscle biopsy technique [16] to obtain intact muscle specimens suitable for in vitro investigation [3]. Additionally, kinetic studies were performed to establish the $V_{\max }$ and $K_{m}$ for non-insulin and insulin-stimulated 3-0-methylglucose transport in muscle specimens obtained from healthy subjects.

\section{Subjects, materials and methods}

\section{Subject characteristics}

The study protocol was reviewed and approved by the institutional ethical committee of the Karolinska Institute and informed consent was received from all subjects prior to participation. The clinical characteristics of the study participants are presented in Table 1 . The diabetic group consisted of thirteen NIDDM patients with a body mass index of $27.8 \pm 0.8 \mathrm{~kg} / \mathrm{m}^{2}$ (mean \pm SEM) (range $22.3-32.0 \mathrm{~kg} / \mathrm{m}^{2}$ ) and disease duration of $6.5 \pm 1.1$ years (range 1-13 years). Glycaemic control, as evaluated by $\mathrm{HbA}_{1 \mathrm{C}}$ was moderate $(8.1 \pm 0.4 \%)$ for this group of NIDDM patients. The normal value for $\mathrm{HbA}_{1 \mathrm{C}}$ in our laboratory is less than $5.5 \%$. Four of the NIDDM patients were treated with sulphonylureas, three with a combined treatment of sulphonylureas and biguanides, two with a combined treatment of sulphonylureas and a subcutaneous injection of insulin, and four with diet. Twenty-three non-diabetic subjects, with a body mass index of $24.9 \pm 0.4 \mathrm{~kg} / \mathrm{m}^{2}$, composed the control group. Three diabetic patients and two of the non-diabetic subjects had moderate hypertension, which in all cases was treated with diuretic medication (furosemide). None of the subjects received beta-adrenergic blockade. All of the participants were non-smokers, and matched for age. In vitro and in vivo assessments of insulin action were performed on separate occasions. On each testing occasion, the subjects reported to the laboratory following an overnight fast, and in the case of the NIDDM patients, prior to administration of any anti-diabetic drug.

\section{Insulin action in vivo}

The study participants were randomly assigned to undergo the Bergman insulin sensitivity test [17] or a euglycaemic-hyperinsulinaemic clamp procedure [18] for determination of insulin action in vivo. During the euglycaemic-hyperinsulinaemic clamp procedure, the non-diabetic and NIDDM participants were clamped at a steady-state blood glucose concentration of $4.8 \pm 0.2 \mathrm{mmol} / \mathrm{l}(n=5)$ and $7.4 \pm 0.1 \mathrm{mmol} / \mathrm{l}(n=5)$, respectively. A bolus insulin infusion $\left(24 \mathrm{nmol} \times \mathrm{kg}^{-1} \times \mathrm{min}^{-1}\right)$ was given for 2 min and hyperinsulinemia was maintained by means of a continuous insulin infusion $\left(6 \mathrm{nmol} \times \mathrm{kg}^{-1} \times \mathrm{min}^{-1}\right)$ for $2 \mathrm{~h}$. This procedure resulted in free insulin concentrations of $401.4 \pm 16.2 \mathrm{pmol} / \mathrm{l}$ and $455.2 \pm 18.0 \mathrm{pmol} / \mathrm{l}$ for the non-diabetic and NIDDM participants, respectively (NS). Whole body glucose utilization was determined by means of a variable glucose infusion with intermittent blood glucose determinations performed every $5 \mathrm{~min}$.

\section{Open muscle biopsy procedure}

Under local anaesthesia (mepivakain chloride, $5 \mathrm{mg} / \mathrm{ml}$ ), two open muscle biopsy specimens $(\sim 300 \mathrm{mg})$ were obtained from the vastus lateralis portion of the quadriceps femoris muscle as previously described [16]. The specimens were placed in oxygenated KHB ( $\mathrm{pH} 7.4)$, containing $5 \mathrm{mmol} / \mathrm{HEPES}(\mathrm{N}-2-\mathrm{Hy}-$ droxyethylpiperazine-N'-2-ethanesulphonic acid), 0.1\% BSA (radioimmunoassay grade), $38 \mathrm{mmol} / 1$ mannitol and $2 \mathrm{mmol} / \mathrm{l}$ pyruvate (as substrate). Smaller muscle strips $(\sim 18 \mathrm{mg})$ were dissected free from the larger muscle specimen, and were mounted on plexi-glass clamps as described earlier $[3,16]$. A smaller biopsy sample $(75-100 \mathrm{mg})$, obtained from the open muscle biopsy incision site by means of a Weil-Blakesley's conchotome [19], was rapidly frozen in liquid nitrogen and subsequently freeze-dried at $-35^{\circ} \mathrm{C}(72 \mathrm{~h})$ for assessment of muscle glycogen content.

\section{Muscle strip in vitro incubation procedure}

After preparation, the mounted muscle strips were placed in individual glass flasks and incubated $(10 \mathrm{~min})$ in KHB media $(2 \mathrm{ml})$ as described above. Throughout the incubation protocol the samples were placed in a shaking water bath $(110 \mathrm{times} / \mathrm{min})$, maintained at a constant temperature $\left(35^{\circ} \mathrm{C}\right)$, and were continuously gassed $\left(95 \% \mathrm{O}_{2} / 5 \% \mathrm{CO}_{2}\right)$. Unless specifically stated, the concentration of BSA, HEPES, and constitutes of the KHB buffer remained constant for all incubation conditions. The muscle samples were transferred to a second KHB incubation solution which contained increasing concentrations of glucose, oleate (cis-9-octadecadienoic acid; solubilized in $1.2 \%$ essentially fatty acid free BSA) or insulin as further described in the figures, and were subsequently incubated for $0.5,1.0$, or $2.0 \mathrm{~h}$. The media concentrations of the oleate or insulin were maintained constant throughout the incubation protocol. A variable amount of mannitol was added to all solutions to keep osmolarity constant $(40 \mathrm{mosmol} / \mathrm{l})$ in the presence or absence of glucose. For experiments in which oleate was included in the media, a variable volume of $1.2 \%$ essentially fatty acid free BSA was added to all medias to maintain a constant concentration of BSA $(0.3 \%)$ between the treatment groups. This slight increase in the media concentration of BSA $(0.1 \%$ to $0.3 \%)$ had no significant effect on the glucose transport rate (J.R.Zierath, L.A. Nolte, and $\mathrm{H}$. Wallberg-Henriksson, unpublished observation). 
Table 1. Clinical characteristics of the study participants and in vivo assessment of insulin action

\begin{tabular}{|c|c|c|}
\hline & NIDDM patients & Non-diabetic subjects \\
\hline \multicolumn{3}{|l|}{ Subject characteristics } \\
\hline $\begin{array}{l}\text { Age (years) } \\
\text { Sex (male/female) } \\
\text { Body mass index }\left(\mathrm{kg} / \mathrm{m}^{2}\right) \\
\text { Duration of diabetes }(\mathrm{years}) \\
\text { Fasting plasma glucose }(\mathrm{mmol} / \mathrm{l}) \\
\mathrm{HbA}_{1 \mathrm{C}}(\%) \\
\text { Fasting serum insulin }(\mathrm{pmol} / \mathrm{l}) \\
\text { Muscle glycogen content } \\
\quad \text { (mmol } \times \mathrm{kg}^{-1} \text { dry weight) }\end{array}$ & $\begin{array}{l}53 \pm 2 \\
12 / 1 \\
27.8 \pm 0.8 \\
6.5 \pm 1.1 \\
10.5 \pm 0.6^{c} \\
8.1 \pm 0.5^{c} \\
97.8 \pm 11.4^{b} \\
427 \pm 35\end{array}$ & $\begin{array}{l}50 \pm 2 \\
22 / 1 \\
24.9 \pm 0.4 \\
5.1 \pm 0.7 \\
4.2 \pm 0.1 \\
54.2 \pm 8.4 \\
430 \pm 25\end{array}$ \\
\hline \multicolumn{3}{|l|}{ In vivo assessment of insulin action } \\
\hline $\begin{array}{l}\text { Insulin sensitivity index } \\
\qquad\left(\times 10^{-4} \mathrm{~min}^{-1} \times \mu \mathrm{U} / \mathrm{ml}\right)\end{array}$ & $1.36 \pm 0.36^{\circ}(n=6)$ & $4.68 \pm 1.13(n=6)$ \\
\hline
\end{tabular}

Values are presented as mean $\pm \mathrm{SEM} ;{ }^{a} p<0.05,{ }^{b} p<0.01,{ }^{c} p<0.001$ significantly different from non-diabetic subjects; ${ }^{d}$ Insulin-mediated glucose utilization assessed at $7.4 \pm 0.1 \mathrm{mmol} / 1$ or $4.8 \pm 0.2 \mathrm{mmol} / \mathrm{glucose}$ for the NDDM and non-diabetic subjects, respectively

One set of experiments was designed to assess the integrity of the muscle cell membranes and to determine the rate of non-facilitated glucose diffusion in the incubated skeletal muscle strips following inhibition of the transport system with cytochlasin B. Cytochlasin B is a fungal metabolite which, when bound to the facilitated glucose transporters, inhibits facilitated D-glucose transport [20]. Muscle strips from non-diabetic subjects were preincubated for $1.0 \mathrm{~h}$ in a glucose free KHB medium, which included insulin $(600 \mathrm{pmol} / 1)$ and cytochlasin B $(50 \mu \mathrm{mol} / \mathrm{l})$. The concentrations of insulin and cytochlasin $B$ were maintained in all of the remaining incubation phases. The muscle strips were then transferred to a fresh KHB preincubation medium containing $5 \mathrm{mmol} / \mathrm{l}$ glucose and were incubated $(1.0 \mathrm{~h})$.

Following the incubations as described above, the muscle strips were transferred to a glucose-free medium where they were rinsed of glucose for $10 \mathrm{~min}$. When muscle strips were utilized for the study of 3-0-methylglucose kinetics, the samples were exposed to fresh glucose-free media for three consecutive 5-min intervals to ensure that glucose was rinsed from the extracellular space.

All muscle strips were transferred from the glucose-free media to a final incubation ( $20 \mathrm{~min}$ ), whereby $3-0-\left[{ }^{3} \mathrm{H}\right]$ methylglucose $(437 \mu \mathrm{Ci} / \mathrm{mmol})$ and $\left[{ }^{14} \mathrm{C}\right]$ mannitol $(8 \mu \mathrm{Ci} / \mathrm{mmol})$ were substituted for unlabelled glucose and mannitol, respectively. Thus, the concentration of 3-0-methylglucose during the final incubation corresponded with the glucose concentration of the initial incubation step. The rate of 3-0-methylglucose transport for the incubated muscle strips was determined as described by Wallberg-Henriksson et al. [21] for the rat epitrochlearis muscle. 3-0-methylglucose transport is expressed per ml of intracellular water.

\section{Biochemical assays and chemicals}

A portion of the freeze-dried muscle biopsy specimen ( $\sim 2 \mathrm{mg}$ ) was dissected free from connective tissue, cleaned of blood, and extracted with a procedure devised by Lowery (for general principles see [22], with specific modifications described in [21]). Glycogen was assayed fluorometrically according to Lowery and Passonneau [22], both in the extract and on the pellet. The results were then combined to give the total glycogen concentration of the muscle. Plasma glucose was analysed by means of a Beckman Glucose Analyzer (Beckman Instrument Inc., Fullerton, Calif., USA). Serum immunoreactive insulin was assayed by the Phadeseph Insulin RIA method (Pharmacia, Uppsala, Sweden). The lower limit of sensitivity of this method was $18 \mathrm{pmol} / \mathrm{l}$ of insulin. $\mathrm{HbA}_{1 \mathrm{C}}$ was determined in plasma by specificion-exchange chromatography, using a commercially available kit (Mono $\mathrm{S}$ HR 5/5, Pharmacia, Uppsala, Sweden).

All chemicals were purchased from Sigma Chemical Co. (St. Louis, Mo., USA), and enzymes from Boehringer Mannheim GmbH Biochemica (Mannheim, Germany). The insulin (Actrapid) was a product of Novo Nordisk A/S (Copenhagen, Denmark). All radioactive products were purchased from New England Nuclear (Boston, Mass., USA).

\section{Statistical analyses}

Results are presented as mean \pm SEM. Whenever comparisons were performed between two singular sets of data, students paired or unpaired $t$-test was employed. To determine the statistical significance of increasing concentrations of glucose on basal and insulin-stimulated glucose transport in the non-diabetic skeletal muscle strips, and to determine the effects of increasing concentrations of insulin on 3-0-methylglucose transport in the diabetic and non-diabetic skeletal muscle strips, a one-way ANOVA was applied. A two-way ANOVA was employed to evaluate the differences between subject groups and insulin dose-response curves. When the ANOVA resulted in a significant $F$-value, the difference between the means was identified by the Newman-Keul post hoc test.

\section{Results}

\section{In vivo assessment of insulin action}

Whole body glucose insulin sensitivity $\left(\mathrm{S}_{\mathrm{I}}\right)$, as evaluated by the minimal model approach according to Bergman [17], was markedly reduced by $70 \%$ in a subgroup of the NIDDM participants, when compared to 


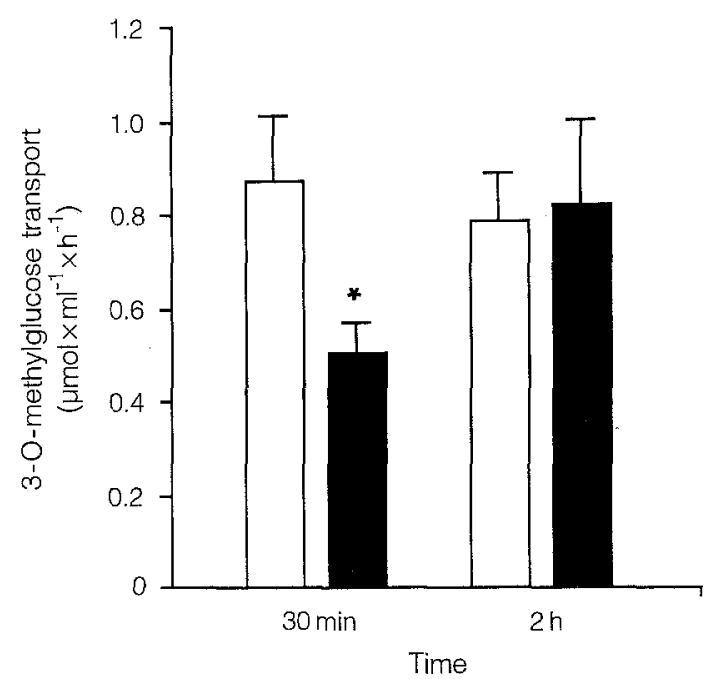

Fig. 1. Normalization of the decreased capacity for insulinstimulated 3-0-methylglucose transport in vitro. Muscle strips from non-diabetic $(\square ; n=8)$ and NIDDM $\mathbf{\mathbf { n }} ; n=7)$ subjects were exposed $(2 \mathrm{~h})$ to $\mathrm{KHB}$ media containing $0.3 \mathrm{mmol} / \mathrm{l}$ oleate, $600 \mathrm{pmol} / \mathrm{l}$ insulin and $4 \mathrm{mmol} / \mathrm{l}$ glucose. Thereafter, an equimolar concentration of 3-0-methylglucose was substituted for glucose, and 3-0-methylglucose transport was assessed. Values are presented as mean \pm SEM. ${ }^{*} p<0.05$ significantly different from the non-diabetic skeletal muscle

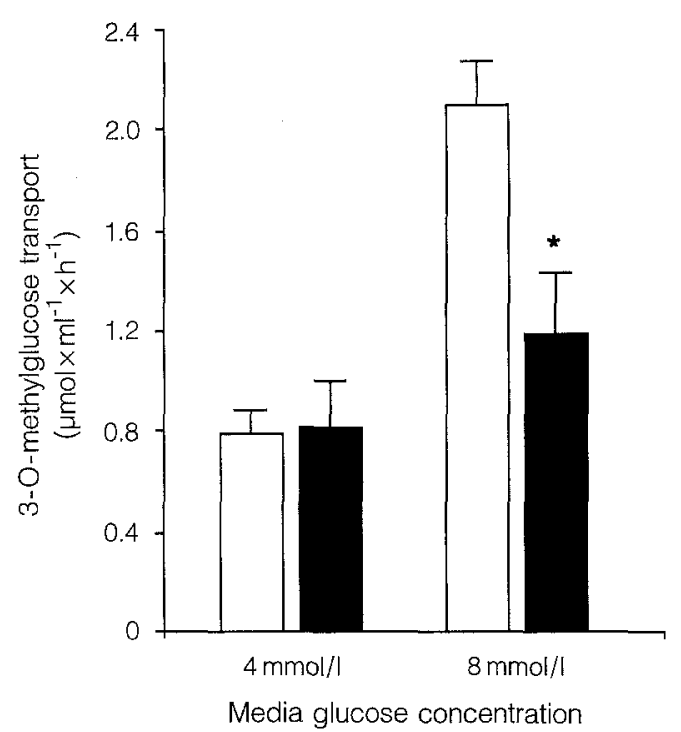

Fig. 2. Insulin-stimulated 3-0-methylglucose transport in skeletal muscle strips obtained from non-diabetic ( $\square$ ) and NIDDM (a) subjects. Skeletal muscle strips were incubated for $2 \mathbf{h}$ in $\mathrm{KHB}$ medium containing $600 \mathrm{pmol} / \mathrm{l}$ insulin and either $4 \mathrm{mmol} / \mathrm{l}$ glucose (non-diabetic $n=8$; NIDDM $n=7$ ) or $8 \mathrm{mmol} / \mathrm{l}$ glucose (non-diabetic $n=9$; NIDDM $n=6$ ) glucose. Thereafter, an equimolar concentration of 3-0-methylglucose was substituted for glucose and the rate of 3-0-methylglucose transport was assessed. Values are presented as mean \pm SEM. $* p<0.05$ significantly different from the non-diabetic skeletal muscle that of the non-diabetic subjects (Table $1, p<0.05$ ). Measurements of peripheral insulin-mediated glucose utilization, as assessed by the euglycaemic-hyperinsulinaemic clamp procedure, revealed that under hyperglycaemic conditions ( $7.1 \pm 0.1 \mathrm{mmol} / \mathrm{l}$ glucose), whole body glucose uptake in the second subgroup of NIDDM patients was not significantly different than the non-diabetic subjects studied at euglycaemia $(4.8 \pm 0.2 \mathrm{mmol} / \mathrm{l}$ glucose) (Table 1$)$.

\section{Normalization of the decreased capacity for insulin-stimulated glucose transport in vitro}

Skeletal muscle strips obtained from the NIDDM patients and the non-diabetic subjects, were incubated in the presence of a low physiological concentration of glucose $(4 \mathrm{mmol} / \mathrm{l})$, with a further addition of $0.3 \mathrm{mmol} / 1$ oleate and $600 \mathrm{pmol} / 1$ insulin. Following a 30 -min in vitro exposure, the muscle strips from the NIDDM patients demonstrated a $40 \%$ lower rate of insulin-stimulated 3-0-methylglucose transport when compared to the muscle strips prepared from the non-diabetic skeletal muscle $(0.50 \pm 0.07$ vs 0.87 $\pm 0.14 \mu \mathrm{mol} \times \mathrm{ml}^{-1} \times \mathrm{h}^{-1}$ for NIDDM and non-diabetic, respectively $p<0.05$; Fig. 1.). The decreased capacity for insulin-stimulated 3-0-methylglucose transport in the muscle strips from the NIDDM patients was normalized after a 2-h incubation in KHB containing $4 \mathrm{mmol} / \mathrm{l}$ glucose $(0.82 \pm 0.18$ vs $0.79 \pm$ $0.10 \mu \mathrm{mol} \times \mathrm{ml}^{-1} \times \mathrm{h}^{-1}$ for NIDDM and non-diabetic, respectively NS). The insulin-stimulated rate of 3-0methylglucose transport in the muscle strips prepared from the non-diabetic subjects was comparable at both time points $\left(0.87 \pm 0.14\right.$ vs $0.79 \pm 0.10 \mu \mathrm{mol} \times \mathrm{ml}^{-1}$ $\times \mathrm{h}^{-1}$, for $30 \mathrm{~min}$ and 2 -h exposure, respectively NS; Fig. 1).

\section{Effect of elevated glucose on the reversal of the decreased capacity for insulin-mediated glucose transport in skeletal muscle from NIDDM patients}

Skeletal muscle strips were incubated for 2 -h in the presence of 4 or $8 \mathrm{mmol} / \mathrm{l}$ glucose to examine the influence of elevated glucose levels on the capacity for insulin-stimulated glucose transport. When muscle specimens were exposed to $8 \mathrm{mmol} / \mathrm{l}$ glucose (Fig. 2), the insulin-stimulated $(600 \mathrm{pmol} / \mathrm{l})$ capacity for glucose transport in the skeletal muscle strips from the NIDDM patients was $\sim 57 \%$ lower than that of the non-diabetic skeletal muscle strips $(1.19 \pm 0.24$ and $2.10 \pm 0.17 \mu \mathrm{mol} \times \mathrm{ml}^{-1} \times \mathrm{h}^{-1}$ for NIDDM and nondiabetic skeletal muscle, respectively $p<0.05$ ). Following 2-h exposure of skeletal muscle specimens to $4 \mathrm{mmol} / 1$ glucose, the rate of insulin-stimulated (600 pmol/l) 3-0-methylglucose transport was comparable between the groups (Fig. 2). 


\section{In vitro assessment of insulin action}

A dose-response relationship for insulin-stimulated 30 -methylglucose transport in the presence of near fasting plasma glucose concentrations for the appropriate groups ( 4 or $8 \mathrm{mmol} / \mathrm{l}$ for the non-diabetic subjects or the NIDDM patients, respectively) was established for the incubated skeletal muscle specimens (Fig. 3). Insulin increased 3-0-methylglucose transport in the skeletal muscle strips obtained from the non-diabetic subjects in a dose-dependent manner, with a half-maximal stimulation of 3-0-methylglucose transport observed in the presence of $600 \mathrm{pmol} / \mathrm{l}$ insulin $(0.72 \pm 0.16$ vs $1.07 \pm 0.16 \mu \mathrm{mol} \times \mathrm{ml}^{-1} \times \mathrm{h}^{-1}$ for basal and insulinstimulated conditions, respectively $p<0.05$ ). Exposure of non-diabetic muscle strips to $1,200 \mathrm{pmol} / \mathrm{l}$ insulin induced a 1.9-fold, maximal response of 3-0-methylglucose transport $(p<0.01)$. An increase in the media insulin concentration from 1,200 to $6,000 \mathrm{pmol} / 1 \mathrm{did}$ not further increase the rate of 3-0-methylglucose transport.

The rate of 3-0-methylglucose transport in the muscle strips obtained from the NIDDM patients was not significantly increased in the presence of $600 \mathrm{pmol} / 1$ insulin $\left(0.94 \pm 0.17 \mathrm{vs} 1.19 \pm 0.24 \mu \mathrm{mol} \times \mathrm{ml}^{-1} \times \mathrm{h}^{-1}\right.$ for basal and insulin-stimulated conditions, respectively NS; Fig. 3). An in vitro exposure of the muscle strips from the NIDDM patients to insulin at concentrations of 1,200 or $6,000 \mathrm{pmol} / \mathrm{l}$, significantly increased the rate of 3-0-methylglucose transport $(1.29 \pm 0.17$ and $1.32 \pm 0.27 \mu \mathrm{mol} \times \mathrm{ml}^{-1} \times \mathrm{h}^{-1}$, respectively $\left.p<0.05\right)$. The fold increase produced by maximal insulin-stimulation of 3-0-methylglucose transport, for the skeletal muscle strips obtained from the NIDDM patients was less than that observed in the muscle strips obtained from the non-diabetic subjects (1.4- vs 1.9-fold for NIDDM and non-diabetic skeletal muscle, respectively $p<0.01$ ). Although the present group of NIDDM patients differed in terms of their anti-diabetic treatment, the in vivo and in vitro response to insulin was similar between the patients receiving insulin therapy and the patients on dietary intervention.

Despite the notably decreased effect of insulin on 30 -methylglucose transport measured in the NIDDM muscle strips, the mean response over the entire doseresponse curve, including the non-insulin-stimulated values of the NIDDM muscle strips pre-incubated at $8 \mathrm{mmol} / \mathrm{l}$ glucose, were not significantly different from those of the non-diabetic skeletal muscle strips pre-incubated at $5 \mathrm{mmol} / 1$ glucose (Fig. 3).

\section{Kinetic studies of non-insulin-stimulated and insulin-stimulated 3-0-methylglucose transport}

Muscle strips were prepared from quadriceps femoris specimens obtained from the non-diabetic subjects and were incubated in the presence of increasing concen-

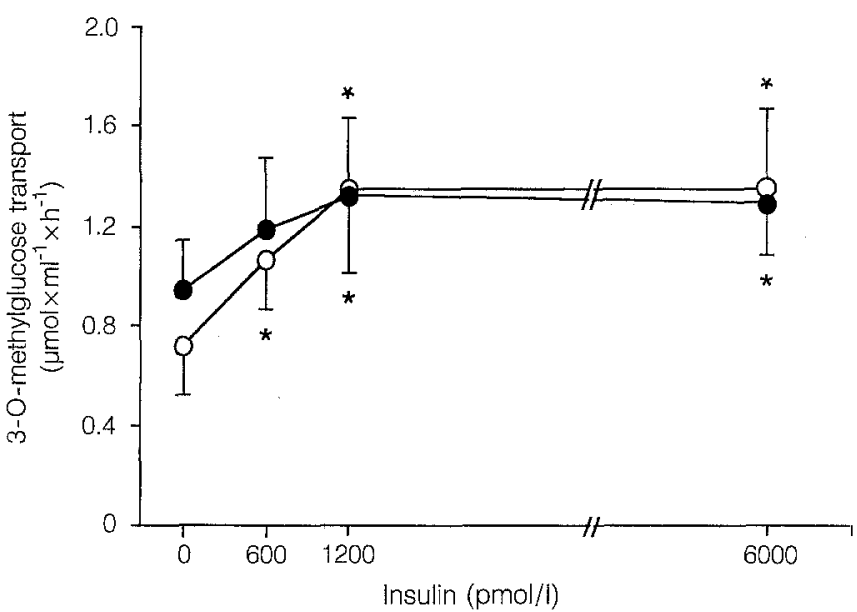

Fig.3. Dose-response relationship for insulin-stimulated 3-0methylglucose transport in skeletal muscle strips incubated at glucose concentrations near fasting plasma concentrations for the appropriate groups. Muscle strips from non-diabetic subjects $(0-0 ; n=6)$ and patients with NIDDM $(-; n=6)$ were incubated ( $2 \mathrm{~h}$ ) in KHB buffer containing $5 \mathrm{mmol} / \mathrm{l}$ (non-diabetic) or $8 \mathrm{mmol} / \mathrm{l}$ (NIDDM) glucose and a further addition of insulin. Thereafter, an equimolar concentration of 3-0-methylglucose was substituted for glucose, and 3-0-methylglucose transport was assessed. Values are presented as mean \pm SEM. $* p<0.05$ significantly different from the corresponding basal rate of 3-0methylglucose transport

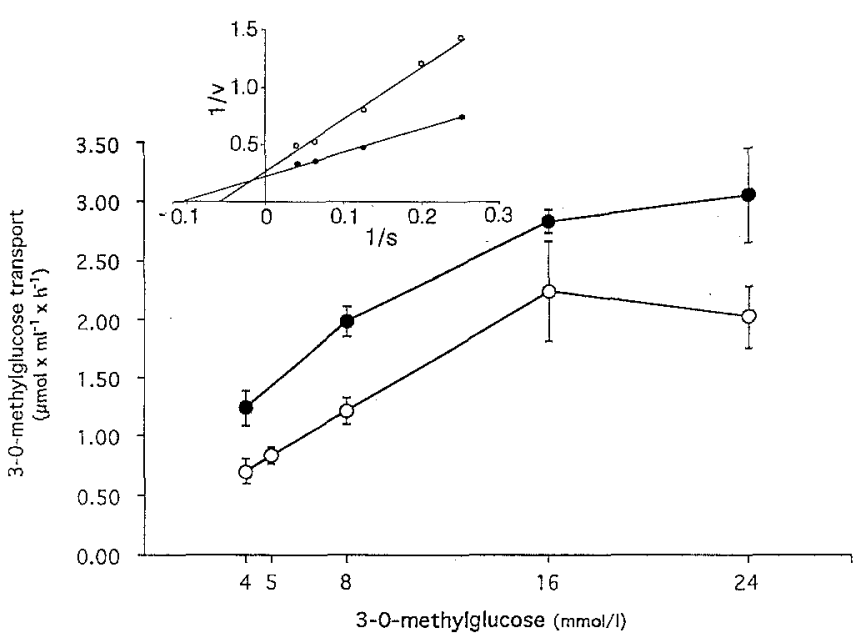

Fig.4. Effect of increasing concentrations of glucose on non-insulin $(\mathrm{O}-\mathrm{O})$ and insulin-stimulated $(\bullet)$ 3-0-methylglucose transport in skeletal muscle specimens. Muscle strips from healthy subjects $(n=9)$ were incubated $(2 \mathrm{~h})$ in KHB medium containing increasing concentrations of glucose with an addition or omission of $600 \mathrm{pmol} / \mathrm{l}$ insulin. Thereafter, equimolar concentrations of 3-0-methylglucose were substituted for glucose, and the rate of 3-0-methylglucose transport was assessed. Reciprocals of the non-insulin and insulin-stimulated rate of 3-0-methylglucose transport vs media 3-0-methylglucose concentration (Lineweaver-Burke analysis) are presented in the inset. Values are presented as mean \pm SEM. The concentration dependence of 3-0-methylglucose transport for the insulin-stimulated conditions was significantly greater when compared to the non-insulin-stimulated condition $(p<0.05)$ 
trations of 3-0-methylglucose (Fig. 4). Non-insulinstimulated 3-0-methylglucose transport increased approximately 2.9-fold (from $0.70 \pm 0.11$ to $2.02 \pm$ $\left.0.43 \mu \mathrm{mol} \times \mathrm{ml}^{-1} \times \mathrm{h}^{-1} ; p<0.01\right)$ over the range of 3-0-methylglucose concentrations tested $(4 \mathrm{mmol} / \mathrm{l}$ to $24 \mathrm{mmol} / \mathrm{l})$. Insulin-stimulated 3-0-methylglucose transport increased approximately 2.5-fold (from $1.24 \pm 0.15$ to $3.07 \pm 0.38 \mu \mathrm{mol} \times \mathrm{ml}^{-1} \times \mathrm{h}^{-1} ; p<0.01$ ) in the presence of increasing glucose concentrations. Lineweaver-Burke analysis of the effect of media glucose concentration on the rate of non-insulin and insulin-stimulated 3-0-methylglucose transport revealed that the reciprocals of the 3-0-methylglucose transport rate vs media $3-0$-methylglucose concentration are well correlated for basal $(r=0.99)$ and insulin-stimulated $(600 \mathrm{pmol} / \mathrm{l})(r=0.99)$ conditions (Fig. 4$)$ in this in vitro human skeletal muscle strip preparation.

The $\mathrm{K}_{\mathrm{m}}$ for non-insulin stimulated 3-0-methylglucose transport was not significantly different from that observed under insulin-stimulated $(600 \mathrm{pmol} / \mathrm{l})$ conditions ( $9.7 \mathrm{vs} 8.8 \mathrm{mmol} / 1$ for basal and insulin-stimulated conditions, respectively NS; Fig. 4). The $\mathrm{V}_{\max }$ for the rate of insulin-stimulated 3-0-methylglucose transport was approximately 1.8 -fold greater than that measured under basal conditions.

\section{Effect of cytochlasin B on insulin-stimulated glucose transport}

The non-facilitated rate of 3-0-methylglucose diffusion $(5 \mathrm{mmol} / \mathrm{l})$ was assessed in insulin-stimulated $(600 \mathrm{pmol} / \mathrm{l})$ skeletal muscle strips following inhibition of the transport system with cytochlasin B. Under these conditions, the rate of 3-0-methylglucose equilibration with the intracellular water amounted to $0.08 \pm$ $0.08 \mu \mathrm{mol} \times \mathrm{ml}^{-1} \times \mathrm{h}^{-1}(n=4)$. Thus, the rate of nonfacilitated $3-0$-methylglucose diffusion is $\sim 5 \%$ of the insulin-stimulated 3-0-methylglucose transport rate.

\section{Biochemical assessments}

Serum glucose and insulin concentration for nondiabetic and NIDDM subjects at the time of the muscle excision are presented in Table 1. Glycogen levels, analysed in a portion of the skeletal muscle biopsy which was frozen immediately upon excision, were similar for the non-diabetic and NIDDM subjects $(430 \pm 25$ vs $427 \pm 35 \mathrm{mmol} \times \mathrm{kg}^{-1}$ dry weight, respectively NS).

\section{Discussion}

We report that isolated skeletal muscle obtained from patients with NIDDM undergoes a reversal of the impaired capacity for insulin-stimulated 3-0-methylglucose transport following a 2 -h in vitro exposure to a low physiological glucose concentration (4 mmol/l). In contrast, when muscle strips from patients with NIDDM were incubated for $2 \mathrm{~h}$ at near the fasting plasma glucose level ( $8 \mathrm{mmol} / \mathrm{l}$ glucose $)$, the rate of insulin-stimulated 3-0-methylglucose transport remained impaired. These findings implicate that glycaemia per se, appears to play a major role in the degree of the impaired capacity for glucose transport in skeletal muscle from patients with NIDDM.

De novo synthesis of GLUT 4 is unlikely to account for the improvement in glucose transport observed in the muscle strips from the patients with NIDDM, since a 2-h in vitro exposure is presumably insufficient to accommodate any significant changes in the expression of total GLUT 4 in skeletal muscle [23, 24]. Furthermore, in contrast to what has been observed in streptozotocin-diabetic rats $[23,25]$, skeletal muscle from lean NIDDM patients has been reported to contain a total GLUT 4 content, which is similar to that of non-diabetic skeletal muscle [26, 27]. Recently, an impaired function [28] or distribution [29] of the GLUT-4 transporter protein has been observed in skeletal muscle from NIDDM patients. Our finding of a normalization of the impaired capacity for insulin-stimulated 3-0methylglucose transport in skeletal muscle from patients with NIDDM, following a 2-h exposure to $4 \mathrm{mmol} / \mathrm{l}$ glucose, implicates that the impaired capacity for insulin-stimulated glucose transport is a consequence of an altered signalling mechanism in the stimulation of glucose transport. Alternatively, the impaired capacity for insulin-stimulated glucose transport in the NIDDM skeletal muscle may result from a defect(s) in the activation or functional capacity of the glucose transporter protein molecules per se.

The mass action of glucose partially compensates for the insulin resistance demonstrated in skeletal muscle from the NIDDM patients by increasing the insulin-independent rate of glucose transport. Since the fasting glycogen levels did not differ between the diabetic and the control muscle biopsies, the transport of glucose into the NIDDM skeletal muscle in vivo appears to be sufficient to maintain normal stores of glycogen under the ambient glucose concentration. Thus, the defect in glucose transport associated with skeletal muscle of patients with NIDDM appears to be secondary to hyperglycaemia. Furthermore, skeletal muscle from patients with NIDDM has been demonstrated to have an increased intracellular concentration of free glucose and glucose 6-phosphate, which may also contribute to the depressed glucose transport capacity in skeletal muscle from NIDDM patients [30].

The present finding that hyperglycaemia per se compensates for the impaired capacity for insulinstimulated glucose transport in NIDDM skeletal muscle by the mass action of glucose, agrees well with in vivo studies $[31,32]$. The mass action of glucose has been demonstrated to partially compensate for the marked decrease in whole body insulin-stimulated glu- 
cose uptake observed under euglycaemic conditions in vivo $[31,32]$. Despite the increase in the insulin-independent component of glucose uptake in NIDDM patients, the insulin-stimulated component of in vivo peripheral glucose utilization [31], as well as the in vitro response of skeletal muscle glucose transport to insulin, remained impaired in a hyperglycaemic environment.

In the skeletal muscle specimens obtained from the non-diabetic subjects, the glucose transport system was not "down-regulated" following the 2 -h in vitro exposure to $8 \mathrm{mmol} / \mathrm{l}$ glucose. This observation was rather unexpected since the diabetic muscle underwent a reversal of the impaired capacity for insulin-stimulated 3-0-methylglucose transport following a 2-h exposure to $4 \mathrm{mmol} / \mathrm{l}$ glucose. However, the time course for the up-regulation of glucose transport, in a system where glucose transport is depressed, may potentially be faster than the down-regulation of an unimpaired glucose transport system. Conceivably, the muscle cells are striving to maintain an optimal capacity for glucose transport and will consequently utilize compensatory mechanisms to maintain a normal level of glucose transport for as long as possible.

The kinetics of whole body glucose uptake have been well characterized in man using in vivo techniques [33-36]. However in vivo, these measurements may be confounded by factors such as skeletal muscle blood flow $[34,37]$, degree of obesity of the subject tested [34], and circulatory hormones [38, 39]. Under in vitro conditions, increasing concentrations of extracellular 3-0-methylglucose increases basal 3-0-methylglucose transport in rat muscle in a dose-dependent manner, with $\mathrm{a} \mathrm{K}_{\mathrm{m}}$ of approximately $6 \mathrm{mmol} / \mathrm{l}[40,41]$. Similar to in vivo reports [33], insulin increases the maximal rate of glucose transport $\left(\mathrm{V}_{\max }\right)$ in isolated rat skeletal muscle without altering the apparent $K_{m}[40,41]$. In the present study, we demonstrate that the $\mathrm{K}_{\mathrm{m}}$ for $3-0$ methylglucose transport in the isolated skeletal muscle strips was in the order of $9 \mathrm{mmol} / \mathrm{l}$, whereas, insulin induced a two-fold increase in the maximal velocity of the transport system without significantly altering the $\mathrm{K}_{\mathrm{m}}$. Thus, these results indicate that in human skeletal muscle, insulin increases the rate of glucose transport by providing additional glucose transport sites at the plasma membrane, rather than increasing the affinity for glucose. The in vitro kinetic data from the present study agree well with studies of whole body glucose uptake in terms of the $\mathrm{K}_{\mathrm{m}}$, but displays a markedly lower $V_{\max }[33,35]$. In healthy subjects, insulin increases the $V_{\max }$ for glucose uptake $\sim 4-5$-fold in vivo, without altering the $\mathrm{K}_{\mathrm{m}}$ of $5-9 \mathrm{mmol} / \mathrm{l}[33,35]$. This discrepancy between in vivo and in vitro rates of glucose uptake may be explained by the observation that insulin action on the tissue level in vivo is affected in part by blood flow changes [34, 35, 37] as well as counterregulatory hormones [38]. Furthermore, the rate of $3-0$-methylglucose transport in the in vitro incubated muscle strips may also be limited by the rate of diffusion of the glucose analogue in the extracellular space of the muscle.

Based on our finding that cytochlasin B inhibited the insulin-stimulated rate of 3-0-methylglucose transport by $\sim 95 \%$, it is unlikely that the muscle cell membranes are damaged by the surgical or muscle strip preparation. The $\sim 5 \%$ rate of non-facilitated 3-0methylglucose diffusion measured in the human skeletal muscle strip preparation is in agreement with the $\sim 6 \%$ passive diffusion reported by Nesher et al. [40] for isolated rat epitrochlearis muscle incubated in vitro.

In conclusion, the present study demonstrates a normalization of the impaired insulin-stimulated glucose transport capacity in insulin-resistant skeletal muscle obtained from NIDDM patients. This normalization is observed following a $2-\mathrm{h}$ in vitro exposure to $4 \mathrm{mmol} / \mathrm{l}$, but not $8 \mathrm{mmol} / \mathrm{l}$ glucose. Furthermore, the impaired glucose transport capacity in skeletal muscle from NIDDM patients appears to be an effective, adaptive response, to protect the cell against an excessive rate of glucose uptake under hyperglycaemic conditions.

Acknowledgements. This study was supported by grants from the Swedish Medical Research Council (5117), the Bank of Sweden Tercentenary Foundation, the Swedish Diabetes Association, the Nordisk Insulin Foundation, the Thurings Foundation, the Wibergs Research Foundation, Gustav V's Research Foundation, and from Novo-Nordisk A/S. J.R.Zierath was supported by a fellowship from the Swedish Medical Research Council (10627).

\section{References}

1. Reaven GM, Olefsky JM (1978) The role of insulin resistance in the pathogenesis of diabetes mellitus. Adv Metab Res 9: 313-331

2. DeFronzo RA, Bonadonna RC, Ferrannini E (1992) Pathogenesis of NIDDM. A balanced overview. Diabetes Care 15:318-368

3. Dohm GL, Tapscott EB, Pories WJ et al. (1988) An in vitro human muscle preparation suitable for metabolic studies. $\mathbf{J}$ Clin Invest 82: 486-494

4. Andréasson K, Galuska D, Thörne A, Sonnenfeld T, Wallberg-Henriksson H (1991) Decreased insulin-stimulated 30 -methylglucose transport in in vitro incubated muscle strips from type II diabetic subjects. Acta Physiol Scand 142: 255260

5. De Fronzo RA, Gunnarsson R, Björkman O, Olsson M, Wahren J (1985) Effects of insulin on peripheral and splanchnic glucose metabolism in noninsulin-dependent (type II) diabetes mellitus. J Clin Invest 76: 149-155

6. Rossetti L, Giaccari A, DeFronzo RA (1990) Glucose toxicity. Diabetes Care 13: 610-630

7. Sasson S, Edelson D, Cerasi E (1987) In vitro autoregulation of glucose utilization in rat soleus muscles. Diabetes 36: 1041-1046

8. Richter EA, Hansen BF, Hansen SA (1988) Glucose-induced insulin resistance of skeletal-muscle glucose transport and uptake. Biochem J 252: 733-737 
9. Sasson S, Cerasi E (1986) Substrate regulation of the glucose transport system in rat skeletal muscle. J Biol Chem 261: 16827-16833

10. Yki-Järvinen H, Helve E, Koivisto VA (1987) Hyperglycemia decreases glucose uptake in type I diabetes. Diabetes 36 : 892-896

11. Unger RH, Grundy S (1985) Hyperglycemia as an inducer as well as a consequence of impaired islet cell function and insulin resistance: implications for the management of diabetes. Diabetologia 28: 119-121

12. Kahn BB, Schulman GI, DeFronzo RA, Cushman SW, Rossetti L (1991) Normalization of blood glucose in diabetic rats with phlorizin treatment reverses insulin-resistant glucose transport in adipose cells without restoring glucose transporter gene expression. J Clin Invest 87:561-570

13. Scarlett JA, Kolterman OG, Ciaraldi TP, Kao M, Olefsky JM (1983) Insulin treatment reverses the postreceptor defect in adipocyte 3-0-methylglucose transport in type II diabetes mellitus. J Clin Endocrinol Metab 56: 1195-1201

14. Foley JE, Kashiwagi A, Verso MA, Reaven G, Andrews J (1983) Improvement in in vitro insulin action after one month of insulin therapy in obese noninsulin-dependent diabetics. J Clin Invest 72: 1901-1909

15. Hollund E, Pedersen O, Sorensen NS (1987) Adipocyte insulin binding and action in moderately obese NIDDM patients after dietary control of plasma glucose: reversal of post-binding abnormalities. Diabetes Care 10: 306-312

16. Zierath JR, Galuska D, Engström § et al. (1992) Human islet amyloid polypeptide at pharmacological levels inhibits insulin and phorbol ester-stimulated glucose transport in in vitro incubated human muscle strips. Diabetologia 35: 26-31

17. Bergman RN, Ider YZ, Bowden CR, Cobelli C (1979) Quantitative estimation of insulin sensitivity. Am J Physiol 236: E667-E677

18. DeFronzo RA, Tobin JD, Andres R (1979) Glucose clamp technique: a method for quantifying insulin secretion and resistance. Am J Physiol 237: E214-E223

19. Henriksson KG (1979) Semi-open muscle biopsy technique. Acta Neurol Scand 59: 317-323

20. Vinten J (1978) Cytochlasin B inhibition and temperature dependence of 3-0-methylglucose transport in fat cells. Biochim Biophy Acta 511: 259-273

21. Wallberg-Henriksson H, Nie Z, Henriksson J (1987) Reversibility of decreased insulin-stimulated glucose transport capacity in diabetic muscle with in vitro incubation: insulin is not required. J Biol Chem 262: 7665-7671

22. Lowery, OH, Passonneau JV (1972) A flexible system of enzymatic analysis. Academic Press, New York

23. Bourey RE, Koranyi L, James DE, Mueckler M, Permutt MA (1990) Effects of altered glucose homeostasis on glucose transporter expression in skeletal muscle of the rat. J Clin Invest 86: $542-547$

24. James DE, Studelska DR, Rodnick KJ (1992) Glucose transporter gene expression in muscle. In: Devlin JT, Horton ES, Vranic M (eds) Diabetes mellitus and exercise. Smith-Gordon, London, pp 45-54

25. Ramlal T, Rastogi S, Vranic M, Klip A (1989) Decrease in glucose transporter number in skeletal muscle of mildly diabetic (streptozotocin-treated) rats. Endocrinology 125: $890-897$
26. Handberg A, Vaag A, Damsbo P, Beck-Nielsen H, Vinten J (1990) Expression of insulin-regulatable glucose transporters in skeletal muscle from type 2 (non-insulin-dependent) diabetic patients. Diabetologia 33: 625-627

27. Pedersen O, Bak JF, Andersen PH et al. (1990) Evidence against altered expression of GLUT1 or GLUT4 in skeletal muscle of patients with obesity or NIDDM. Diabetes 39: $865-870$

28. Garvey WT, Maianu L, Hancock JA, Golichowski AM, Baron A (1992) Gene expression of GLUT4 in skeletal muscle from insulin-resistant patients with obesity, IGT, GDM, and NIDDM. Diabetes 41: 465-475

29. Vogt B, Mühlbacher C, Carrascosa J et al. (1992) Subcellular distribution of GLUT 4 in the skeletal muscle of lean type 2 (non-insulin-dependent) diabetic patients in the basal state. Diabetologia 35 : 456-463

30. Vaag A, Damsbo P, Hother-Nielsen O, Beck-Nielsen $\mathbf{H}$ (1992) Hyperglycaemia compensates for the defect in insulin-mediated glucose metabolism and in the activation of glycogen synthase in the skeletal muscle of patients with type 2 (non-insulin-dependent) diabetes mellitus. Diabetologia 35: $80-88$

31. Revers RR, Fink R, Griffin J, Olefsky JM, Kolterman OG (1984) Influence of hyperglycemia on insulin's in vivo effects in type II diabetes. J Clin Invest 73: 664-672

32. Kelley DE, Mandarino LJ (1990) Hyperglycemia normalizes insulin-stimulated skeletal muscle glucose oxidation and storage in noninsulin-dependent diabetes mellitus. J Clin Invest 86: 1999-2007

33. Gottesman I, Mandarino L, Verdonk C, Rizza R, Gerich J (1982) Insulin increases the maximum velocity for glucose uptake without altering the Michaelis constant in man. Evidence that insulin increases glucose uptake merely by providing additional transport sites. J Clin Invest 70: 1310-1314

34. Laakso M. Edelman SV, Olefsky JM, Brechtel G, Wallace P, Baron AD (1990) Kinetics of in vivo muscle insulin-mediated glucose uptake in human obesity. Diabetes 39: 965-974

35. Edelman SV, Laakso M, Wallace P, Brechtel G, Olefsky JM, Baron AD (1990) Kinetics of insulin-mediated and non-insulin-mediated glucose uptake in humans. Diabetes 39: 955964

36. Fink RI, Wallace P, Brechtel G, Olefsky JM (1992) Evidence that glucose transport is rate-limiting for in vivo glucose uptake. Metabolism 41: 897-902

37. Laakso M, Edelman SV, Brechtel G, Baron AD (1992) Impaired insulin-mediated skeletal muscle blood flow in patients with NIDDM. Diabetes 41: 1076-1083

38. Boström M, Nie Z, Goertz G, Henriksson J, Wallberg-Henriksson H (1989) Indirect effect of catecholamines on development of insulin resistance in skeletal muscle from diabetic rats. Diabetes 38: 906-910

39. Laakso M, Edelman SV, Brechtel G, Baron A (1992) Effects of epinephrine on insulin-mediated glucose uptake in whole body and leg muscle in humans: role of blood flow. Am J Physiol 263: E199-E204

40. Nesher R, Karl I, Kipnis DM (1985) Dissociation of effects of insulin and contraction on glucose transport in rat epitrochlearis muscle. Am J Physiol 249: C226-C232

41. Karl IE, Gavin JR III, Levy J (1990) Effect of insulin on glucose utilization in epitrochlearis muscle of rats with streptozotocin-induced NIDDM. Diabetes 39:1106-1115 